DOI: https://doi.org/10.24867/10BE19Jokovic

\title{
RAZVOJ KONCEPTA VEKTORSKOG UPRAVLJANJA ASINHRONOM MAŠINOM U POGONU OPŠTE NAMENE
}

\section{DEVELOPMENT OF CONCEPTUAL VECTOR CONTROL ALGORITHM FOR INDUCTION MACHINE DRIVE}

\author{
Marko Joković, Darko Marčetić, Fakultet tehničkih nauka, Novi Sad
}

\section{Oblast - ELEKTROTEHNIKA I RAČUNARSTVO}

Kratak sadržaj - U ovom radu je prikazana univerzalna procedura za podešavanje vektorskog kontrolera $u$ pogonu opšte namene sa asinhronom mašinom. Polazeći od matematičkog modela vektorskog kontrolera, definiše se skup koraka za sintezu softversko/hardverskih modula koje uključuje pomenuti kontroler za pravilnu orijentaciju polja. Eksperimentalna verifikacija metode je izvršena na pogonu opšte namene sa AM upravljanog putem mikroprocesorskog sistema baziranog na DSPIC30F4011.

Ključne reči: Vektorsko upravljanje, Asinhrona mašina, Regulacija

Abstract The paper presents the universal procedure for synthesis of vector controller within the IM drive. Starting from the mathematical model of vector controller, the guideline steps for setting the relevant modules of field oriented controller are given. Performance evaluation of microcontroller based IM drive is given on DSPIC30F4011 control platform.

Keywords: Vector control, induction machine, regulation

\section{UVOD}

Visoke performanse upravljanja u naizmeničnim elektromotornim pogonima sa $A M$ su moguće jedino upotrebom koncepta vektorske kontrole. Ovakav vid upravljanja se danas sve više primenjuje čak i u okviru pogona opšte namene koji su se tradicionalno bazirali na jednostavnijim upravljačkim algoritmima (skalarno upravljanje u otvorenoj sprezi, kontrola klizanja...). Tome značajno doprinosi razvoj energetske i upravljačke elektronike zasnovane na jeftinim i komercijalno dostupnim mikroprocesorima.

Pogoni opšte namene se proizvode u masovnim serijama i često imaju za zahtev smanjenje broja raspoloživih senzora. Time se umanjuje cena pogona koji postaje konkurentan na tržištu proizvoda. Stožiji zahtevi tržišta po pitanju performansi rada nameću potrebu za definisanjem jednostavne ali univerzalne procedure za kalibraciju kontrolera vektorskog upravljanja.

$\mathrm{U}$ ovom radu, jedna takva procedura je predstavljena $\mathrm{i}$ detaljno definisana.

\section{NAPOMENA:}

Ovaj rad proistekao je iz master rada čiji mentor je bio dr Darko Marčetić, red. prof.

\section{VEKTORSKI MODEL AM}

Posmatra se matematički model AM u sinhronorotirajućem $d q$ sistemu osa dat u [1]. Ukoliko se unesu sledeća ograničenja unutar kontrolera:

$$
\psi_{r d}=\left|\boldsymbol{\psi}_{r}\right|, \quad \psi_{r q}=0
$$

$d q$ sistem se orijentiše na fluks rotora i postiže se pozicioniranje na njegov ugao.

Dobija se redukovani vektorski model $A M$ trećeg reda, koji prikazan u prostoru stanja ima oblik:

$$
\begin{aligned}
\frac{d}{d t}\left[\begin{array}{c}
i_{s d} \\
i_{s q} \\
\psi_{r d}
\end{array}\right]= & {\left[\begin{array}{ccc}
-\frac{R_{\sigma}}{L_{\sigma}} & \omega_{d q} & \frac{L_{m}}{T_{r} L_{r} L_{\sigma}} \\
-\omega_{d q} & -\frac{R_{\sigma}}{L_{\sigma}} & -\frac{\omega L_{m}}{L_{r} L_{\sigma}} \\
\frac{L_{m}}{T_{r}} & 0 & -\frac{1}{T_{r}}
\end{array}\right]\left[\begin{array}{c}
i_{s d} \\
i_{s q} \\
\psi_{r d}
\end{array}\right]+\left[\begin{array}{cc}
\frac{1}{L_{\sigma}} & 0 \\
0 & \frac{1}{L_{\sigma}} \\
0 & 0
\end{array}\right]\left[\begin{array}{l}
u_{s d} \\
u_{s q}
\end{array}\right] } \\
& \left(L_{m} / T_{r}\right) i_{s q}-\left(\omega_{d q}-\omega\right) \psi_{r d}=0
\end{aligned}
$$

Orijentacijom polja po 1), dinamička jednačina za $q$ komponentu fluksa rotora postaje algebarska odakle se uočava redukcija reda modela.

Posledica pravilne orijentacija polja jeste raspregnuta kontrola momentom $m_{e l}$ i fluksom $A M \psi_{r d}=\psi_{r}$ koji se računaju kao:

$$
\begin{gathered}
m_{e l}=\frac{3}{2} P \frac{L_{m}}{L_{r}} \psi_{r d} i_{s q}=\frac{3}{2} P \frac{L_{m}^{2}}{L_{r}} i_{s d} i_{s q} \\
\frac{d}{d t} \psi_{r d}=-\frac{1}{T_{r}} \psi_{r d}+\frac{L_{m}}{T_{r}} i_{s d} \stackrel{d / d t=0}{\longrightarrow} \psi_{r d}=L_{m} i_{s d}
\end{gathered}
$$

Praktična realizacija orijentacije polja FOC (eng. Field Oriented Controller) se vrši indirektno računom klizanja na osnovu algebarske relacije 3):

$$
\begin{gathered}
\omega_{k}=\frac{L_{m}}{T_{r}} \frac{i_{s q}}{\psi_{r d}}=\frac{1}{T_{r}} \frac{i_{s q}}{i_{s d}} \\
\omega_{d q}=\omega+\omega_{k} \\
\theta_{d q}=\int \omega_{d q} d t
\end{gathered}
$$

Za potrebe regulacije struje kao drugog preduslova za vektorsku kontrolu $A M$, strujne jednačine u (2) se prepisuju u pogodan oblik za željenu analizu:

$$
\begin{gathered}
u_{s d}=R_{s} i_{s d}+L_{\sigma} \frac{d i_{s d}}{d t}-\omega_{d q} L_{\sigma} i_{s q} \\
u_{s q}=R_{s} i_{s q}+L_{\sigma} \frac{d i_{s q}}{d t}+\omega_{d q} L_{\sigma} i_{s d}+\omega_{d q} \frac{L_{m}}{L_{r}} \psi_{r d}
\end{gathered}
$$

Relacije 1) -8) su polazna osnova za definisanje procedure za kalibrisanje vektorski upravljanog pogona $A M$. 


\section{PROCEDURA ZA PODEŠAVANJE VEKTORSKOG KONTROLERA AM}

Na Slici 1 prikazan je kompletan blok dijagram vektorskog pogona $A M$ sa svim relevantnim blokovima.

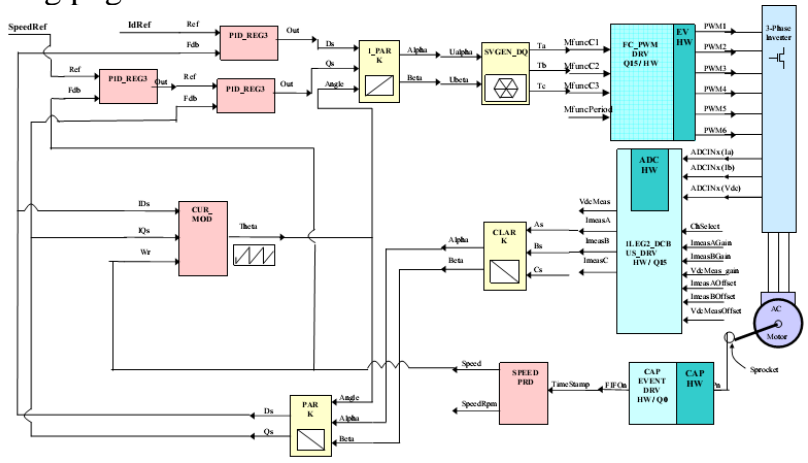

Slika 1. Kompletan blok dijagram vektorski upravljanog pogona $A M$

Testiranje vektorskog kontrolera $A M$ po predloženoj proceduri se sprovodi kroz nekoliko faza:

- $\quad$ Test VSI - test naponskog izvora

- Test CRVSI - strujno regulisani naponski izvor, metoda za podešavanje pojačanja PI regulatora struje

- $\quad$ Test $F O C$ - podešavanje orijentacije polja

- Test Brzinska petlja - metoda podešavanje pojačanja PI regulatora brzine

\subsection{Test VSI}

Prva faza testa vektorskog kontrolera $A M \mathrm{u}$ osnovu obuhvata testiranje mehanizma za pravljenje vektora napona unutar pogona sa invertorskim pretvaračem.

Na Slici 2 prikazan je deo pogona kojim se ostvaruje prva faza testa - impulsno širinska modulacija putem prostornih vektora SVPWM (eng. Space Vector Pulse Width Modulation).

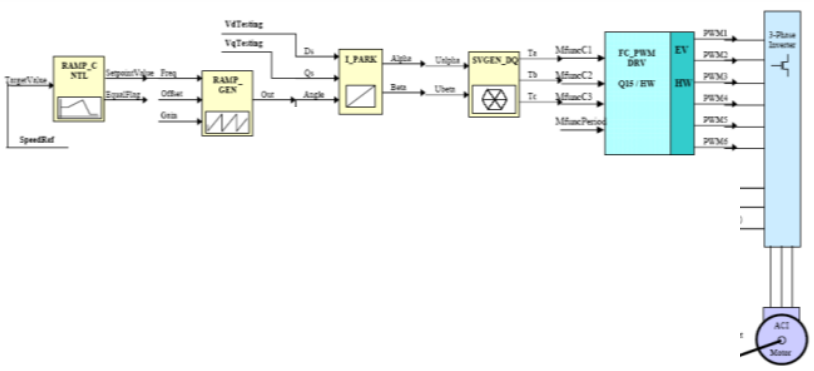

Slika 2. Blok dijagram za testiranje faze I - VSI

Blokovima RAMP_CTRL i RAMP_GEN se zadaju vrednosti učestanosti napajanja Freq i naponskih referenci VdTesting i VqTesting. Blokovima I_PARK i SV_GEN se procesuiraju ulazni signali i računaju vremena vođenja za $P W M$ periferiju.

\subsection{Test CRVSI}

Vektorska kontrola je specijalan vid strujne kontrole kod koje se upravlja pored amplitude i faznim stavom struje $u$ odnosu na referentni fluks rotora. Iz tog razloga jako je važno obezbediti strujnu regulaciju u pogonu u slučaju da se energija dobija iz naponskog VSI pretvarača.

Koncept strujno regulisanog naponskog izvora tzv. CRVSI se može obezbediti ukoliko dinamika uvedene strujne petlje u okviru kontrolnog algoritma značajno ubrza odziv struje u odnosu na prirodnu dinamiku uspostavljanja iste. Celokupna konfiguracija za testiranje CRVSI je prikazana na Slici 3. U odnosu na konfiguraciju sa Slike 2 uvodi se povratna sprega po struji sa svim elementima za procesuiranje dok se signali napona dobijaju kao izlaz iz strujnih regulatora. Učestanost napajanja iznosi nula, čime se utiskuju $D C$ signali koji sprečavaju da se $A M$ obrće.

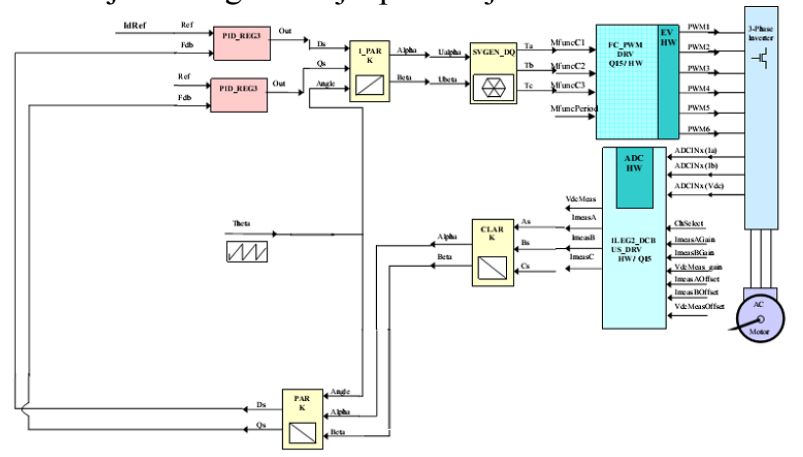

Slika 3 Blok dijagram za testiranje faze II - CRVSI CRVSI posmatra napone kao upravljačke veličine kojima se potrebno upravljati na način da se utiskuje željeni vektor struje AM. U tom pravcu, koriste se relacije 7) i 8) koje opisuju zakonitosti uspostavljanja struje pri pobudnim naponskim signalima. Izvodi se funkcija prenosa od napona do struje sa zanemarenjem sporopromenljivih članova usled obrtnih elektromotornih sila kao i efekata sprezanja osa usled utiskivanja $D C$ signala kada je $\omega_{d q}=0$, [2]. Funkcije prenosa strujnog podsistema se opisuju filtarskom strukturom niskopropusnika opsega prvog reda:

$$
\begin{aligned}
& i_{s d}(s)=\frac{1 / R_{s}}{1+T_{\sigma} s} u_{s d}(s) \\
& i_{s q}(s)=\frac{1 / R_{s}}{1+T_{\sigma} s} u_{s q}(s)
\end{aligned}
$$

Ukoliko se raspolaže informacijom o parametrima otpora namotaja statora $R_{s}$ i ekvivalentne vremenske konstante namotaja mašine $T_{\sigma}$ može se iskoristiti kao pogodan Dahlin-ov algoritam za sintezu parametara regulatora [3]. Algoritam uvažava u obzir diskretni rad kontrolera sa periodom $T$ kao i kašnjenje pretvarača $\tau$ i posmatra funkciju prenosa objekta $u$ vidu filtra prvog reda sa transportnim kašnjenjem:

$$
G_{o b}(s)=\frac{K_{i n v} \cdot 1 / R_{s}}{1+s T_{\sigma}} \cdot e^{-\tau s}
$$

gde je $K_{i n v}=u_{D C} / \sqrt{3}$ pojačanje pretvarača. Optimalni parametri po Dahlin algoritmu su:

$$
\begin{gathered}
K_{p}=\frac{1-e^{-\lambda T}}{K \cdot\left(e^{\frac{T}{T_{1}}}-1\right) \cdot\left[1+N \cdot\left(1-e^{-\lambda T}\right)\right]} \\
\left.K_{i}=K_{p} \frac{T}{T_{i}}=K_{p}\left(e^{\frac{T}{T_{1}}}-1\right)\right)
\end{gathered}
$$

gde su redom:

- $\quad \lambda$ - parametar koji definiše širinu propusnog opsega strujne regulacione konture (brzinu uspostavljanja odziva struje),

- $\quad N$ - broj perioda transportnog kašnjenja,

\subsection{Test FOC}

Treća test faza vektorskog pogona $A M$ podrazumeva kalibraciju bloka za orijentaciju polja $d q$ koordinatnog 
sistema na fluks rotora. Pokazano je da se orijentisanjem sistema na fluks rotora dobija raspregnuta kontrola fluksa i momenta u pogonu putem upravljačkih komponenti vektora struja statora. Uz prethodno testiran CRVSI ovim je omogućena minimalna konfiguracija vektorskog kontrolera elektromotornog pogona sa $A M$.

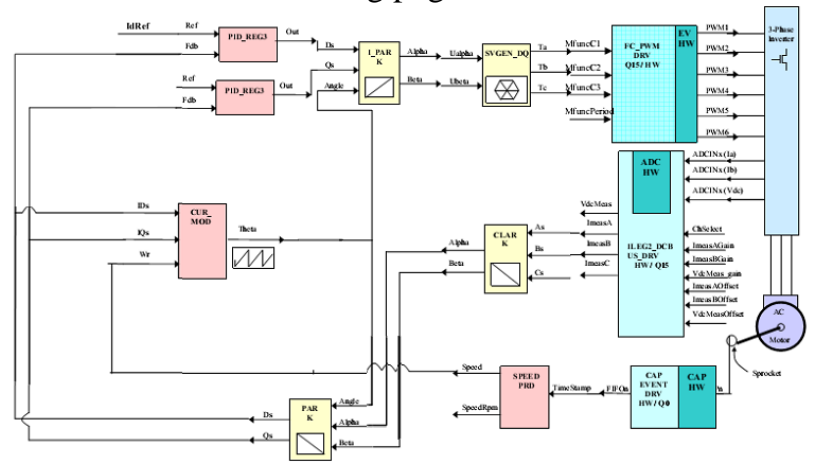

Slika 4 Blok dijagram za testiranje faze III - FOC

Test FOC pored CRVSI konfiguracije uključuje dodatni blok $C U R \_M O D$ koji je zanosnovan na 6). Na osnovu komponenti vektora struje statora i vremenske konstante rotora $T_{r}$ blok daje na izlazu signale $\omega_{d q}$ i $\theta_{d q}$ koji se koriste u okviru blokova za transformacije koordinata PARK i IPARK.

Ukoliko se parametar inverzne vremenske konstante rotora u mikrokontroleru poklopi sa istim parametrom u stvarnom pogonu, postići će se 1) odnosno 4) i 5). Promena struje statora $d$ ose će rezultovati samo promenom fluksa rotora u mašini, promena $q$ komponente struje statora će direktno menjati momenat $A M$. Neophodno je napomenuti da je ovaj test potrebno raditi pri ukočenom rotoru, tj.u stanju kratkog spoja pogona.

Ovim se onemogućuje obrtanje rotora $A M$ te ne postoji opasnost da se mašina usled značajnih vrednosti postignutom momenta pokrene. Treći ulaz u blok CUR_MOD Speed može se izjednačiti sa nulom u tom slučaju te je učestanost napajanja jednak učestanosti klizanja u pogonu.

Koraci za kalibraciju vremenske konstante rotora su redom nabrojani:

- Utiskivanje $d$ komponente struje statora u $A M$

- Zatim se daje profil skokovite reference komponente struje po $q$ osi u ekvidistantnim vremenskim intervalima

- Na osnovu podataka o vrednostima $q$ komponente struje rotora, izračunatih odgovarajućih klizanja kao i momenata AM neophodno je sačiniti linearnu korelaciju

- Mera odstupanja od linearne korelacije (standardna devijacija, modus/medijana...) treba da obezbedi mehanizam za adaptaciju parametra inverzne vremenske konstante na način da se ponovnim ponavljanjem prethodnih koraka ista smanji

- U slučaju pronalaska kalibracionog parametra inverzne vremenske konstante rotora kojom je mera odstupanja linearne zavisnosti momenta od klizanja minimalna postupak se prekida a vrednost parametra se proglašava za referentnu

\subsection{Test Brzinska petlja}

Poslednji test vektorskog pogona $A M$ upravljanog po brzini obrtanja rotora jeste zatvaranje povratne sprege po brzini. Blok dijagram pogona za ovaj test je već prikazan na Slici 1 .

Signali na ulazu u regulatore struja $d q$ osa se ne zadaju ručno već se dobijaju kao izlaz iz PI regulatora brzine.

Test brzinske petlje najpre podrazumeva sprovođenje metode za merenje mehaničke inercije $J$ pogona. Metode zaustavljanja, zaleta sa konstantnim momentom $m_{e}$ itd pri neopterećenom stanju u pogonu mogu da posluže u svrhe proračuna ovog parametra.

$$
J=m_{e} / \frac{d \omega}{d t} \approx m_{e} / \frac{\Delta \omega}{\Delta t}
$$

Nakon merenja momenta inercije moguće je nekom od analitičkih metoda za proračun parametara regulatora brzine dobiti vrednosti proporcionalnog i integralnog pojačanja kojim se obezbeđuju željeni zahtevi pogona.

Koristi se procedura za pronalaženje parametara po kriterijumu minimizacije sume greške [4]:

$$
\begin{gathered}
K_{p}=0.2027 \frac{2 J}{T_{\omega}} \\
K_{i}=0.03512 \frac{2 J}{T_{\omega}}
\end{gathered}
$$

gde je $T_{\omega}$ definisana perioda rada brzinske petlje.

Ovom metodom se obezbeđuje kritično aperiodičan odziv na odskočnu pobudu. Metoda uvažava u obzir diskretan rad regulatora brzine a kao ulazni podatak koristi određeni parametar J po 14).

\section{EKSPERIMENTALNA VERIFIKACIJA REZULTATA PREDLOŽENE PROCEDURE}

Prototip pogona se sastoji od dve identične $A M$, mehanički povezane u motor-generator grupu za svrhu opterećivanja u pogonu. Energetska elektronika se sastoji od trofaznog invertora koji pretvara DC u AC pomoću PWM upravljačke strategije. Frekvencija PWM nosioca je podesno izabrana na vrednost $f_{P W M}=15151 \mathrm{~Hz}$. Digitalna kontrola koja uključuje vektorski kontroler, sa opisanom procedurom je izvedena putem digitalnog mikrokontrolera zasnovanog na dsPIC30F4011. Ovaj mikroprocesor zadovoljava sve kriterijume koji se postavljaju pred jedan moderni pogon visokih performansi za primenu u oblasti električne vuče i transporta. Ova postavka je povezana na DC napajanje koje se sastoji od četiri $12 \mathrm{~V}$ baterije povezane na red kako bi formirale stabilan $48 \mathrm{~V}$ izvor napajanja za pretvarač. Postavka je prikazana na Slici 5.

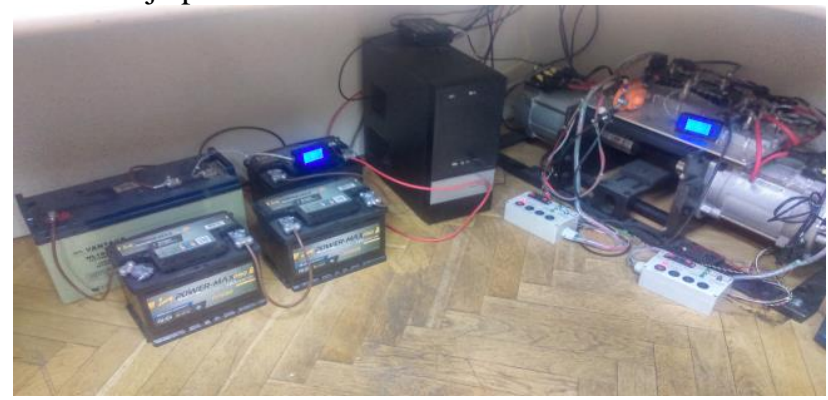

Slika 5 Postavka pogona za eksperiment

Električni parametri korišćene $A M$ su: $R_{s}=5.5 \mathrm{~m} \Omega$, $L_{\gamma s}=L_{\gamma r}=28 \mu \mathrm{H}, T_{r}=255 \mathrm{~ms}, R_{F e}=3.2 \Omega$

Observacijom signala vremena vođenja $A, B$ i $C$ kao izlaza iz $S V P W M$ bloka u funkciji ugla modulacije i međufaznih signala na Slici 6 ze test VSI može se zaključiti: 
- (Analogni) Signali vremena vođenja faza pretvarača iz SVPWM predstavljaju offset-ovane kvazi sinusoidalne signale

- Treći harmonik signala koji je nultog redosleda simetrije je prisutan jedino $\mathrm{u}$ faznom signalu, međufazni signal ima samo osnovni harmonik

- Offset signal nije prisutan u međufaznim naponima pretvarača

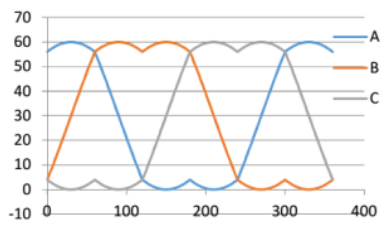

a)

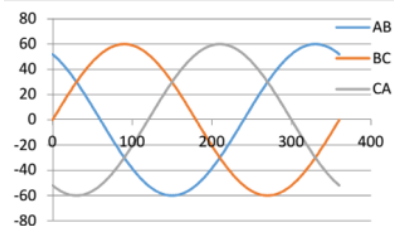

b)
Slika 6. Izgled a) SVPWM vremena vođenja faza invertora $i$ b) međufaznih napona pretvarača

Na Slici 7 prikazani su eksperimentalni odzivi struja na odskočni profil reference po Dahlin-ovom kriterijumu za više vrednosti propusnog opsega $\lambda$. Uočava se aperiodičan odziv struje koji je u saglasnosti sa Dahlin algoritmom. Odziv regulacione strukture je brži od prirodnog odziva $A M$ definisanog sa prirodnom učestanošću $1 / T_{\sigma}=100 \mathrm{~Hz}$. Perioda rada strujne petlje odgovara periodi $P W M$ signala, $T=1 / f_{P W M}=66 \mu s$.

Is [A] Regulacija bez filtra u povratnoj sprezi - lamda $=0.25 \mathrm{kHz}$

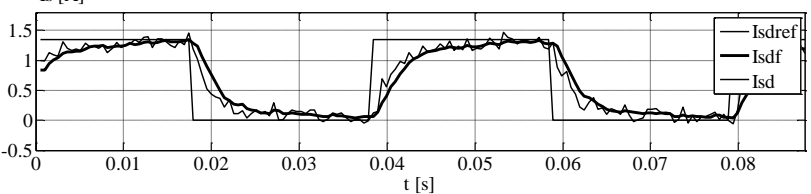

Is [A] Regulacija sa filtrom u povratnoj sprezi - lamda $=0.25 \mathrm{kHz}$

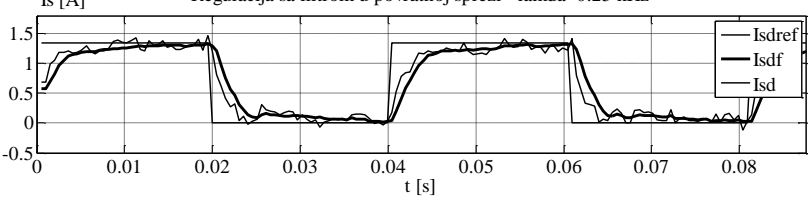

a)

Regulacija bez filtra u povratnoj sprezi - lamda $=0.5 \mathrm{kHz}$

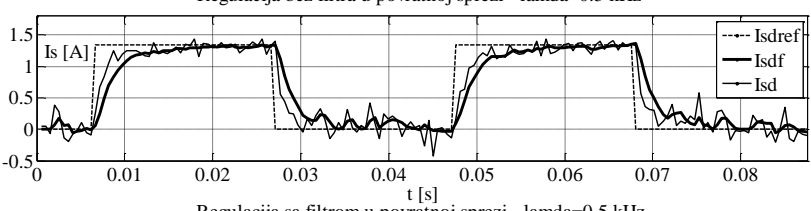

Regulacija sa filtrom u povratnoj sprezi - lamda $=0.5 \mathrm{kHz}$

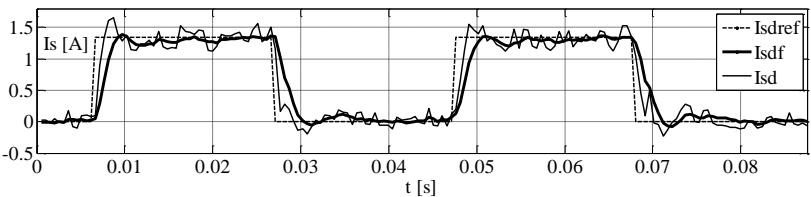

b)

Slika 7. Eksperimentalni odzivi struja na odskočni profil reference po Dahlin-ovom kriterijumu a) pri $\lambda=250 \mathrm{~Hz}$ i b) $\lambda=500 \mathrm{~Hz}$ korišćenog $\mathrm{AM}$

Na Slici 8 prikazan je eksperimentalni test za određivanje momenta inercije pogona. Zadaje se profil q struje odskočni profil struje trajanja $\Delta t=0.5 \mathrm{~s}$ kojim se uspostavlja elektromagnetni momenat. Brzina pri konstantnom momentu se promeni za iznos $\Delta \omega=$ $350 \mathrm{rad} / \mathrm{s}$, što daje vrednost za momenat inercije:

$$
J=\frac{m_{e} \Delta t}{\Delta \omega}=0.0041 \mathrm{kgm}^{2}
$$

$\mathrm{Na}$ kraju, prikazani su i eksperimentalni rezultati odziva brzine (gornji) i struje (donji grafici) pogona $A M$ na profil brzine, referenca brzine $250 \mathrm{o} / \mathrm{min}$ tipa rampa funkcije trajanja $0.5 \mathrm{~s}$, desno, i $2.5 \mathrm{~s}$, levo. Sinteza parametara je izvršena na osnovu 15)-16) sa periodom rada brzinskog regulatora $T_{\omega}=20 \mathrm{~ms}$.
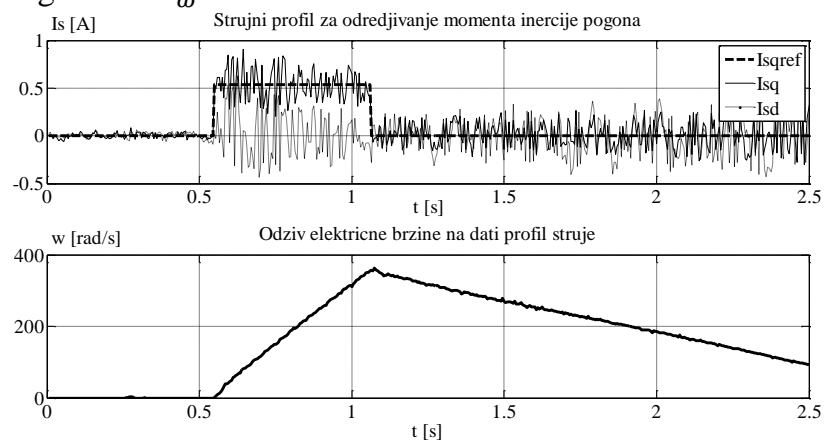

Slika 8. Momentni profil za određivanje parametra $J$

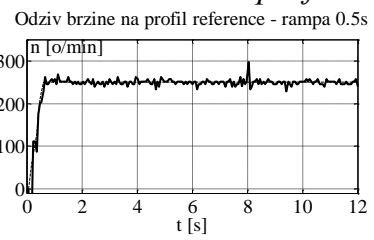

Odziv brzine na profil reference - rampa $2.5 \mathrm{~s}$
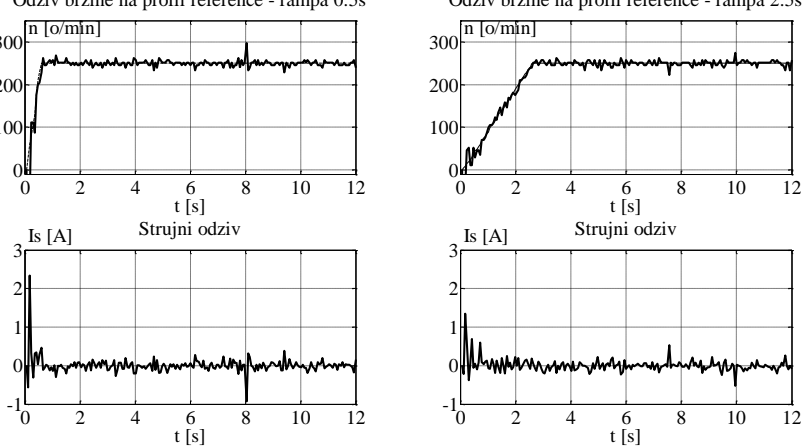

Slika 9. Odzivi brzine (gornji) $i$ struje (donji grafici) pogona na profil brzine, referenca brzine $250 \mathrm{o} / \mathrm{min}$ tipa rampa funkcije trajanja $0.5 \mathrm{~s}$, desno, i $2.5 \mathrm{~s}$, levo

\section{ZAKLJUČAK}

U ovom radu je prikazana praktična procedura za kalibraciju vektorskog kontrolera pogona $A M$ opšte namene. Dat je detaljan opis svih relevantnih koraka sinteze blokova koji sačinjavaju ovaj kontroler. $\mathrm{Na}$ primeru digitalnog pogona $A M$, prikazani su eksperimentalni rezultati testova koji potvrdjuju validnost predložene praktične procedure.

\section{LITERATURA}

[1] Darko Marčetić: „Mikroprocesorsko upravljanje energetskim pretvaračima“, Fakultet tehničkih nauka, Novi Sad, 2014.

[2] V. Vučković, „Električni pogoni“, Akademska misao, 2002.

[3] Dahlin E.B. „Designing and tuning digital controllers, Part I and II“", Instrum. Control. Systms, vol. 41, pp. 77-83 and pp. 87-91, Jun./Jul. 1968.

[4] Slobodan Vukosavić: „Digitalno upravljanje električnim pogonima“, Akademska misao, Beograd, 2003.

\section{Kratka biografija:}

Marko Joković rođen je u Kladovu 1996. god. Master rad na Fakultetu tehničkih nauka iz oblasti Elektrotehnike i računarstva - Energetska elektronika i električne mašine odbranio je 2020.god.

Darko Marčetić je redovni profesor na Fakultetu tehničkih nauka u Novom Sadu, na Katedri za Energetsku elektroniku i pretvarače. Oblast interesovanja su mu digitalno upravljanje elektromotornim pogonima i optimalna kontrola. 